\title{
Factors Influencing Cystic Ovarian Disease in Holstein Friesian (HF) Crossbred Cattle
}

\author{
Harini Hombalegowda ${ }^{1^{*}}$, Nagaraja Ramakrishnappa ${ }^{2}$, Naveen Kumar Siddaraju ${ }^{3}$, Nagaraja Chikkalure \\ Sringeshwaraiah ${ }^{4}$, Sudha Guelal ${ }^{5}$
}

\begin{abstract}
${ }^{1} \mathrm{PhD}$ Scholar, Department of Animal Genetics and Breeding, Veterinary College, Hebbal, Bengaluru, Karnataka, India
${ }^{2}$ Dean, Veterinary College, Gadag, Department of Animal Genetics and Breeding, Veterinary College, Hebbal, Bengaluru, Karnataka, India

${ }^{3}$ Associate Professor (I/C) \& Head, Department of Animal Genetics and Breeding, Veterinary College, Hebbal, Bengaluru, Karnataka, India

${ }^{4}$ Principal Scientist and Head, AICRP on Poultry, Department of Poultry Science, Veterinary College, Hebbal, Bengaluru, Karnataka, India

${ }^{5}$ Associate Professor (I/C), Department of Veterinary Gynaecology and Obstetrics, Veterinary College, Hebbal, Bengaluru, Karnataka, India
\end{abstract}

*Address for Correspondence: Harini Hombalegowda, Ph.D. Scholar, Department of AGB, Veterinary College, Hebbal, Bangalore, Karnataka, India

E-mail: harinigowda822@gmail.com

Received: 15 Nov 2018/ Revised: 21 Feb 2019/ Accepted: 22 Apr 2019

\begin{abstract}
Background: Cystic Ovarian Disease (COD) is an important ovarian dysfunction and a major cause of reproductive failure in dairy cattle. The present study was carried out with the objective to determine the factors influencing Cystic Ovarian Disease in $\mathrm{HF}$ crossbred cows.

Methods: The study was undertaken on 155 Holstein Friesian (HF) crossbred cows. Age, parity and body condition score (BCS) were recorded. Statistical analysis was done to know the influence of age, parity and BCS on the occurrence of COD by Graph Pad Prism software.

Results: Significantly higher proportions of COD cases were reported in the animals of 5 to 7 years age group and least in the age group of greater than 7 years old. Significantly higher proportions of COD cases were observed in $2^{\text {nd }}$ and $3^{\text {rd }}$ lactation cows and less in heifers as well as animals in $4^{\text {th }}$ and above lactation. The incidence of ovarian cysts was highest in the cows having good body condition scoring (BCS-3), followed by cows having very good BCS (3.5), followed by fat cows (BCS-4) and least in animals having BCS 2 and 5.

Conclusion: The study revealed that the age, parity and BCS of the animal influence the risk factors for cystic ovarian diseases; however, similar such studies are needed to support the current results.
\end{abstract}

Key-words: BCS, Crossbred cattle, Cystic ovarian disease, HF, Gynaecological disorders, Parity

\section{INTRODUCTION}

Ovarian cyst (OC) is a common and economically significant condition of dairy cattle ${ }^{[1]}$. Various gynaecological disorders impede the progress of dairy

\section{How to cite this article}

Hombalegowda H, Ramakrishnappa N, Siddaraju NK, Sringeshwaraiah NC, Guelal S. Factors Influencing Cystic Ovarian Disease in Holstein Friesian (HF) Crossbred Cattle. SSR Inst. Int. J. Life Sci., 2019; 5(3): 2317-2321.

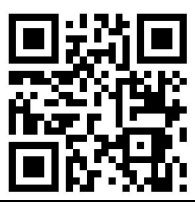

industry ${ }^{[2]}$. Epidemiological surveys on different gynaecological diseases help in diagnosis and proper treatment of infertility cases in field condition ${ }^{[3]}$. Simultaneously with this selection for production characteristics, dairy cow fertility has declined significantly ${ }^{[4]}$. Cystic cows have extent calving-toconception and calving intervals by many days over unaffected one, resulting in significant economic losses in the dairy industry ${ }^{[5]}$. A number of factors have been associated with an increased risk of Cystic Ovarian Disease (COD) at the individual animal level. These include parity, constitutional weakness, body condition 
score and genetic factors ${ }^{[6]}$. Age, parity and BCS (Body Condition Score) are the important factors postulated to influence the occurrence of COD. Milk yield has been identified as a risk factor in some studies but not in others. It is likely that this effect is dependent on the energy status of the cow, rather than the milk yield. High milk yield may contribute to negative energy balance resulting in metabolic and hormonal adaptations, which influence follicle growth and cyst development ${ }^{[7]}$. In the present study an effort is made to know the influence of age, parity and BCS on the occurrence of COD.

\section{MATERIALS AND METHODS}

The present study was undertaken on 155 Holstein Friesian (HF) crossbred cows from villages of Ramanagara district, adjoining villages of Bengaluru district and cows maintained at Department of Livestock Farm Complex (LFC), Veterinary College, Bengaluru, India. This study was conducted for a period of two years between January 2016 to December 2017. The experimental animals were divided into two groups viz., COD affected (105) and COD unaffected/ apparently healthy (50) animals as a control group. Identification of COD affected HF crossbred cattle was done based on the history, clinical symptoms, per rectal palpation and ultrasound scanning of ovarian structures.

The ovaries were palpated to detect the cystic condition. Cysts were diagnosed with their specific characteristics during rectal palpation ${ }^{[8]}$. During rectal palpation, COD affected cases were identified based on their large-sized ovaries having a fluctuating structure. The follicular cysts were identified based on their thinner-walled, tensed and distended structure than the softer thicker walled luteal cysts. The follicular cyst and luteal cyst has a smooth surface, indicating the absence of ovulation. Following rectal palpation, animal was subjected to transrectal ultrasonographic examination of ovaries using real-time b-mode scanner equipped with 5-7.5 $\mathrm{MHz}$ linear array portable ultrasonographic machine (Honda Electronics, HS-2000, Japan) to confirm the presence of cysts. Animals that formed the COD unaffected/ control group were selected based on the history of regular calving, estrus and confirmation through per rectal examination. Reproductive parameters such as age, parity, Body Condition Score (BCS), milk yield, calving complications, puerperal complications and number of services per conception were recorded using questionnaire.
The age parity and BCS (Body Condition Score) of the animals were recorded. The active reproductive age of cows was categorized into three groups' viz., less than five years old, five to seven years old and more than seven years old. Parity of the cow was classified into five group's viz., heifer, $1^{\text {st }}, 2^{\text {nd }}, 3^{\text {rd }}$ and $4^{\text {th }}$ and above. The BCS was visually scored using a 5 point system (1= Emaciated, $2=$ Thin, 3=Average, $4=$ Fat, and $5=$ Obese) as described by Edmonson et al. ${ }^{[9]}$.

Statistical Analysis- Statistical analysis was done to know the influence of age, parity and BCS on the occurrence of COD by GraphPad Prism software ${ }^{[10]}$.

\section{RESULTS}

In the present study, the influence of age, parity and COD on occurrence of COD in HF crossbred cows was evaluated. Out of 105 affected animals 31 animals were less than 5 years of age, 61 animals were in the age group of 5-7 years, 13 animals were more than 7 years of age. In parity group, 14 animals were heifers, 21 animals were of first parity, 27 animals were of second parity, 26 animals were of third parity, and 17 animals were of fourth and above parity. In BCS group, 77 animals were of good BCS, 12 animals were having very good BCS, 11 animals were fat, 3 animals were having moderate BCS and one animal was obese. Significance was checked by GraphPad Prism software by comparing observed and expected frequencies.

The highest incidence of COD was recorded in $2^{\text {nd }}$ lactation, in the age group of 5-7 years and also animals having good BCS. Significantly $(\mathrm{P}<0.001)$ higher proportions of $C O D$ cases were reported in the animals of 5 to 7 years age group followed by cows in the age group of lesser than 5 years and least in the age group of greater than 7 years. Significantly $(P<0.001)$ higher proportions of COD cases were observed in $2^{\text {nd }}$ and $3^{\text {rd }}$ lactation cows and less in heifers as well as animals in $4^{\text {th }}$ and above lactation. The nutritional status of affected cows was graded in terms of BCS. Animals were classified on 1-5 score scale with an increments of 0.5 score, which indicates emaciated, very poor, poor, moderate, good, very good, fat, adipose, and obese animal. The incidence of ovarian cysts was highest in the cows having good body condition scoring (BCS-3), followed by cows having very good BCS (3.5), followed by fat cows (BCS-4) and least in animals having BCS 2 and 5. 
No COD cases were found in the animals of BCS $1,1.5$ and 4.5.The details of the proportion of COD cases observed in age, parity and BCS groups are presented in Table 1.

Table 1: Proportion of cystic ovary with respect to age, parity and BCS

\begin{tabular}{|c|c|c|c|c|c|c|}
\hline S. No. & Parameters & \multicolumn{2}{|c|}{ Group/ Category } & No. of animals & Animals \% & $\begin{array}{c}\text { Chi square } \\
\text { P-value }\end{array}$ \\
\hline & \multirow{3}{*}{ Age } & \multicolumn{2}{|c|}{$<5$ Years } & 31 & 29.52 & \\
\hline \multirow[t]{2}{*}{1} & & \multicolumn{2}{|c|}{ 5-7 Years } & 61 & 58.10 & $<0.001$ \\
\hline & & \multicolumn{2}{|c|}{$>7$ Years } & 13 & 12.38 & \\
\hline \multirow{5}{*}{2} & & \multicolumn{2}{|c|}{ Heifer } & 14 & 13.33 & \\
\hline & Parity & \multicolumn{2}{|c|}{$1^{\text {st }}$} & 21 & 20.00 & \\
\hline & & \multicolumn{2}{|c|}{$2^{\text {nd }}$} & 27 & 25.71 & $<0.001$ \\
\hline & & \multicolumn{2}{|c|}{$3^{\text {rd }}$} & 26 & 24.76 & \\
\hline & & $4^{\text {th }}$ anc & & 17 & 16.20 & \\
\hline \multirow[t]{10}{*}{3} & $\mathrm{BCS}$ & Description & BCS & & & \multirow{10}{*}{$<0.001$} \\
\hline & & Emaciated & 1.0 & 0 & 0 & \\
\hline & & Very poor & 1.5 & 0 & 0 & \\
\hline & & Poor & 2.0 & 1 & 0.95 & \\
\hline & & Moderate & 2.5 & 03 & 2.86 & \\
\hline & & Good & 3.0 & 77 & 73.33 & \\
\hline & & Very good & 3.5 & 12 & 11.43 & \\
\hline & & Fat & 4.0 & 11 & 10.48 & \\
\hline & & Adipose & 4.5 & 0 & 0 & \\
\hline & & Obese & 5.0 & 01 & 0.95 & \\
\hline
\end{tabular}

$\mathrm{BCS}=\mathrm{BCS}=$ Body condition score

\section{DISCUSSION}

Age, parity and BCS were the important factors postulated to influence occurrence of COD. The highest incidence in the cows above 4 years of age, followed by cows in the age group of 2-4 years and lowest in the age group of $1-2$ years ${ }^{[11]}$. The highest incidences of ovarian cysts occur in the 3-5 year age group of in Holstein cows ${ }^{[12]}$. The incidence of cystic ovarian disease was highest in $2^{\text {nd }}$ parity and was reduced thereafter, as reported by Roberts ${ }^{[13]}$. Contrarily, Mimoune et al. ${ }^{[14]}$ have reported a higher incidence of COD in $3^{\text {rd }}$ lactation, HernendezLedezma et al. ${ }^{[15]}$ was observed that the incidence of cystic ovary increased from $8.4 \%$ in primiparous cows to $25.9 \%$ in cows of $5^{\text {th }}$ lactation. In the present study, no cyst was observed beyond $5^{\text {th }}$ lactation, which was similar to that reported by Bhattacharyya et al. ${ }^{[16]}$. Out of $105 \mathrm{HF}$ crossbreds examined, 14 heifers were affected by $C O D$ and it may be due to the genetic nature of the disease. The likelihood of COD occurrence increases with parity. This may be the result of other pathological and physiological conditions which are related to increasing parity, e.g. milk fever ${ }^{[17]}$. The COD incidence was reported more in $4^{\text {th }}$ parity in a study conducted in Norwegian dairy cattle by Nelson et al. ${ }^{[18]}$. Stadnik et al. [19] reported that the group with $\mathrm{BCS} \leq 3.75$ had lower ovarian cystic cases $(8.98 \%$ animals), when compared with other BCS groups of cows with BCS $4-4.25$ (22.86\% of animals) and $\geq 4.50$ ( $21.50 \%$ animals). Normally, excessive BCS is highly related to ovarian cystic cases ${ }^{[20]}$. BCS significantly $(P<0.05)$ affected the ovarian cysts in Fleckvieh cows. Especially over-conditioning may be referred to as weak fertility or nutrition programs in dairy farms. That's why preventing cows from high BCS should principally be considered to obtain fertile cows [19]. Further, body condition may be expected to fall if feed intake declines during periods of high heat and 
humidity ${ }^{[21]}$. During late lactation, the cow in 200 days of lactation and the BCS should be between 2.75 and 3.50 ${ }^{[22]}$. In the current study, all the animals were in mid and late lactation and no animals were in early lactation. Most of the animals in good and have very good BCS so, no NEB is seen in these animals.

\section{CONCLUSIONS}

The incidences of ovarian cysts were highest in the cows aged more than five years and above, followed by cows in the age group of below 5 years and least in the age groups over more than 7 years of age. This shows that the age, parity and BCS are the possible risk factors for COD in crossbred dairy cattle, especially in HF crossbreds.

However, further studies leading such results are needed to be conducted in a large number of experimental samples to ascertain the results. Therefore these risk factors should be evaluated in the larger population prior to their use in the animal breeding.

\section{ACKNOWLEDGMENTS}

This is a part of Ph.D. thesis, funded by KVAFSU, Bidar, so we are all thankful to the University. The technical assistance was given us all advisory members during the tenure of our research. Hence, we are greatly indebted to our all the teachers and particularly our guide $\mathrm{Dr}$. Nagaraja R.

\section{CONTRIBUTION OF AUTHORS}

Research concept- Harini Hombalegowda, Nagaraj Ramakrishnappa

Research design- Harini Hombalegowda, Nagaraj Ramakrishnappa

Supervision- Nagaraj Ramakrishnappa, Naveen Kumar Siddaraju, Nagaraja Chikkalure Sringeshwaraiah, Sudha Guelal

Materials- Harini Hombalegowda

Data collection- Harini Hombalegowda

Data analysis and Interpretation- Harini Hombalegowda, Naveen Kumar Siddaraju, Nagaraja Chikkalure Sringeshwaraiah, Sudha Guelal

Literature search- Harini Hombalegowda

Writing article- Harini Hombalegowda

Critical review-Nagaraj Ramakrishnappa, Nagaraja Chikkalure Sringeshwaraiah, Naveen Kumar Siddaraju, Sudha Guelal

Article editing- Harini Hombalegowda, Nagaraj Ramakrishnappa, Naveenkumar Siddaraju
Final approval-Nagaraj Ramakrishnappa, Naveen Kumar Siddaraju, Nagaraja Chikkalure, Sringeshwaraiah, Sudha Guelal

\section{REFERENCES}

[1] Johnson WH, Coates AE. An update on cystic ovarian disease. In: Proceedings of the 15th International Congress on Animal Reproduction, Porto Seguro, Brazil, Porto Seguro, BA: ICAR, 2004; pp. 60-65.

[2] Raju KGS, Venugopal Naidu K, Rao KS. Incidence of reproductive disorders in buffaloes under field conditions of Andhra Pradesh. Indian J. Anim. Reprod., 2007; 28(1): 46-47.

[3] Selvaraju M, Veerapandian C, Kathiresan D, Chandrahasan $C$. Incidence of bovine reproductive disorders. Indian Vet. J., 2005; 82(5): 556.

[4] Butler WR. Energy balance relationships with follicular development, ovulation and fertility in postpartum dairy cows. Livest. Prod. Sci., 2003; 83: 211-18.

[5] Jeengar K, Chaudhary V, Kumar A, Raiya S, Gaur M, et al. Ovarian cysts in dairy cows: old and new concepts for definition, diagnosis and therapy. Anim. Reprod., 2014; 11(2): 63-73.

[6] Youngquist R, Threlfall W. Ovarian follicular cysts. Current Therapy in Large Animal Therio. St. Louis, MO: Saunders Elsevier, 2006; pp. 379-83.

[7] Vanholder T, Opsomer G, De Kruif A. Aetiology and pathogenesis of cystic ovarian follicles in dairy cattle: a review. Reprod. Nutr. Dev., 2006; 46: 105-19.

[8] Dabas YPS. Cystic ovarian degeneration in cattle-A review. Indian Vet. Med. J., 1998; 22: 1-8.

[9] Edmonson AJ, Lean IJ, Weaver LD, Farver T, Webster G. A body condition scoring chart for Holstein cows. J. Dairy Sci., 1989; 72: 68-78.

[10]Graphpad Prism Version 6.05 for Windows, graphpad software, san diego california usa, www.graphpad.com".

[11]Pushp MK. Ovarian cysts and hormonal profiles in dairy cows and approaches for therapy. MVSc thesis, submitted to Rajastan University of veterinary and animal sciences, Bikaner, India, 2016.

[12]Noseir WMB, Metwally KK, Negm NS. Using double dose of $\mathrm{GnRH}$ for reducing incidence of cystic ovaries in cows. Alexandria J. Vet. Sci., 2013; 39: 124-32.

[13]Roberts SJ. Veterinary Obstetrics and Genital Diseases: Theriogenology, Edwards Brothers Inc. Ann. Arbor. M.I., 1998; pp. 478-94. 
[14]Mimoune N, Kaidi R, Azzouz MY, Zenia S, Benaissa $\mathrm{MH}$, et al. Investigation on diagnosis and metabolic profile of ovarian cysts in dairy cows. Kafkas Univ. Vet. Fak. Derg., 2017; 23(4): 579-86. doi: 10.9775/kvfd.2017.17394.

[15]Hernendez-Ledezma JJ, Arenas P, Dominquez LF, De Fernandez CL. Factors associated with the occurrence of ovarian cysts in dairy cattle. Tecnica Pecuria en Mexico, 1984; 47: 88-94.

[16]Bhattacharyya HK, Mujeeb-U-Rehman F, Bhat FA. Ovarian Cyst in Crossbred Cattle of Temperate Region-A Retrospective Study of 54 Cases. J. Adv. Vet. Res., 2016; 6(4): 108-11.

[17]Fleischer $\mathrm{P}$, Metzner $\mathrm{M}$, Beyerbach $\mathrm{M}$, Hoedemaker $\mathrm{M}$, Klee $\mathrm{W}$. The relationship between milk yield and the incidence of some diseases in dairy cows. J. Dairy Sci., 2001; 84: 2025-35. doi: 10.3168/jds.S00220302(01)74646-2.
[18]Nelson ST, Martin AD, Osreras O. Risk factors associated with cystic ovarian disease in Norwegian dairy cattle. Veterinary Act. Scandinavica, 2010; 52: 60.

[19]Stadnik L, Atasever S, Duchacek J. Effects of body condition score and daily milk yield on reproduction traits of Czech Fleckvieh cows. Anim. Reprod., 2017; 14(1): 1264-69.

[20]Zulu VC, Sawamukai Y, Nakada K, Kida K, Moriyoshi M. Relationship among insulin like growth factor-I, blood metabolites and post partum ovarian function in dairy cows. J. Vet. Med. Sci., 2002; 64: 879-85.

[21]Neary M, Yager A. Body Condition Scoring in Farm Animals Michael Neary, Extension Animal Scientist Ann Yager, Animal Sciences Student Purdue University Department of Animal Sciences, 2002.

[22]Mishra S, Kumari K, Dubey A. Body Condition Scoring of Dairy Cattle: A Review. Research \& Reviews: J. Vet. Sci., 2016; 2(1): 58-65. 